\title{
Dysembryoplastic neuroepithelial tumour: insight into the pathology and pathogenesis
}

\author{
Iwona Sontowska ${ }^{1}$, Ewa Matyja ${ }^{2}$, Jacek Malejczyk ${ }^{1}$, Wieslawa Grajkowska ${ }^{3}$ \\ ${ }^{1}$ Department of Histology and Embryology, Center for Biostructure Research, Medical University of Warsaw, ${ }^{2}$ Department \\ of Experimental and Clinical Neuropathology, Mossakowski Medical Research Centre Polish Academy of Sciences, Warsaw, \\ ${ }^{3}$ Department of Pathology, The Children's Memorial Health Institute, Warsaw, Poland
}

\begin{abstract}
Dysembryoplastic neuroepithelial tumour (DNT) is categorized as a benign glioneuronal neoplasm affecting children and young adults with chronic epileptic seizures. It is characterized by predominant intracortical localization and nodular architecture. Dysembryoplastic neuroepithelial tumour usually demonstrates a distinctive morphological pattern with a specific glioneuronal element but occasionally, its morphological picture is heterogeneous and unspecific. Thus, considering the morphology of DNT, three different histopathological subtypes are distinguished: simple, complex, and non-specific and diffuse. The DNT lesions are often related with focal cortical dysplasia (FCD) type IIIb, which is postulated to play a role in epileptogenicity. Moreover, the accompanying inflammation process might be implicated in DNT-related epileptogenesis.

Dysembryoplastic neuroepithelial tumour is generally characterized by favourable prognosis and good results of surgical treatment. The pathogenesis and molecular mechanisms involved in DNT development remain uncertain. The main molecular findings are connected with BRAF alterations and activation of RAS/ERK, PI3K/AKT and MTOR signalling pathways.

The present review summarizes the clinical, histopathological and molecular findings of DNT. The classification controversy, morphological heterogeneity and diagnostic problems are also discussed.
\end{abstract}

Key words: DNT, dysembryoplastic neuroepithelial tumour, histopathological variants, BRAF, $m T O R, D N T$ - pathology and pathogenesis.

\section{Introduction}

Dysembryoplastic neuroepithelial tumour (DNT) is a benign, glioneuronal neoplasm that is included in the group of neuronal and mixed neuronal-glial tumours, according to the revised $4^{\text {th }}$ edition of current 'WHO Classification of Tumours of the Central Nervous
System' 2016 [46]. This slowly growing tumour corresponds histologically to WHO grade I [37].

Dysembryoplastic neuroepithelial tumour was first described in 1988 by Daumas-Duport et al. [17] as a distinct clinico-pathological entity associated with drug-resistant seizures, which affects children 
and young adults. Typically, the lesion is located in the cerebral cortex, particularly in the mesial temporal lobe. It exhibits multinodular architecture and appears in several different histopathological forms: 1) simple, 2) complex, 3) non-specific and diffuse. The most common clinical presentation is a drugresistant epilepsy of a partial complex type, with earlyonset and long duration from weeks to decades. The resection of the lesion is recommended in symptomatic cases. The stabilization of epileptic seizures has been demonstrated after total or even subtotal resection [12]. Occasionally, the recurrences and spontaneous or post radiation anaplastic transformation to high-grade gliomas have been noted [27].

\section{Localization}

Typically, the DNT lesion is located supratentorially in the cerebral cortex with a predilection for the mesial temporal lobe, less commonly for the frontal lobe $[5,12,60]$. It can be also found in other sites, including the septum pellucidum, caudate nucleus, brain stem and cerebellum [66]. Extremely rarely, the DNT located inside the ventricles, area of the corpus callosum and pericallosal region has been reported $[2,11,23]$.
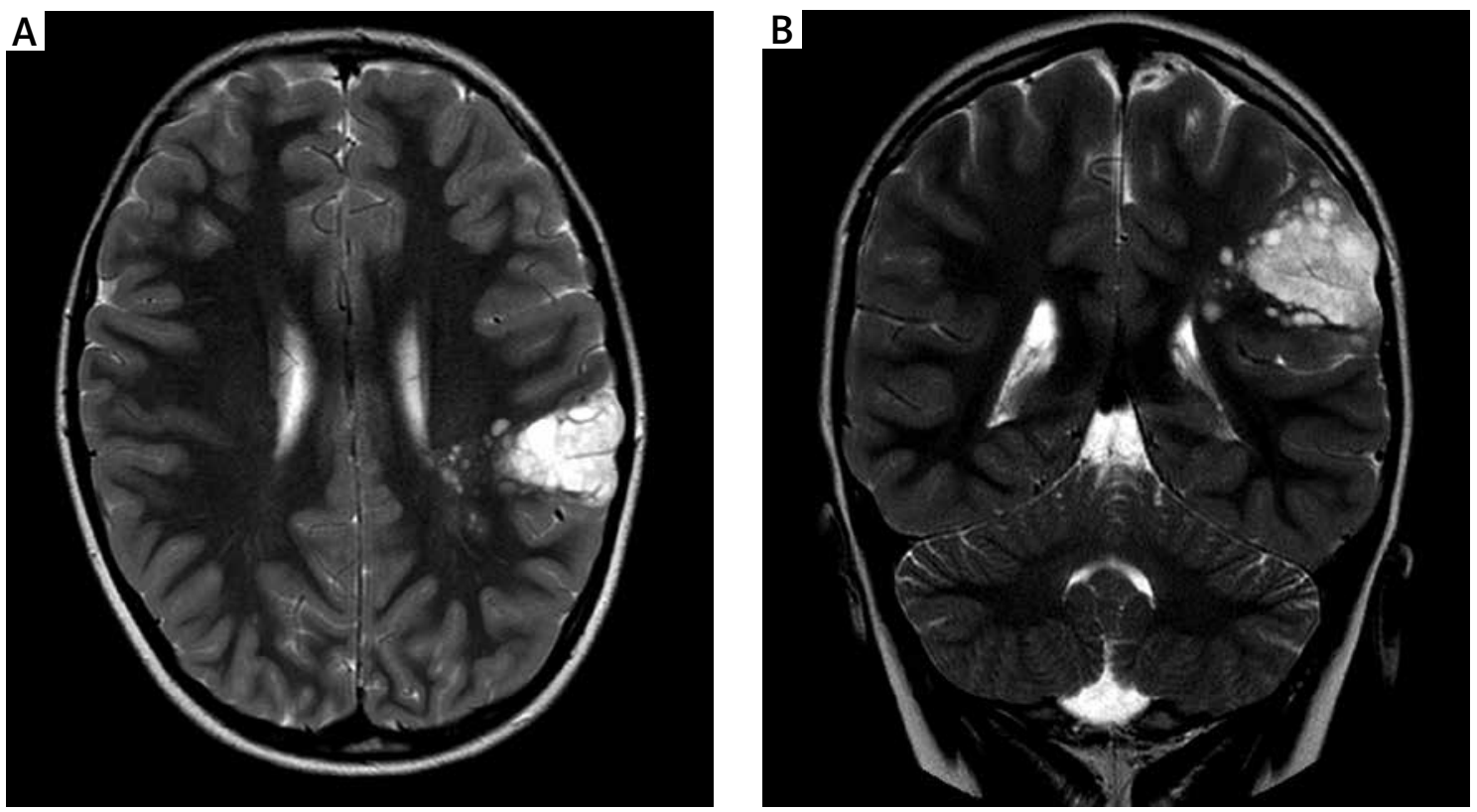

Fig. 1. Magnetic resonance images (MRI) of dysembryoplastic neuroepithelial tumour (DNT). A) The multinodular intracortical lesion of high signal intensity on axial T2-weighted MR image. B) Coronal T2-weighted MRI with hyperintense cortical abnormality (Courtesy of Professor M. Roszkowski). 
effects on midline structures and contrast enhancement are not typical for DNT [36,67]. The internal septation and hyperintense "ring sign" at the periphery of the lesion might be revealed by MRI FLAIR sequence. The magnetic resonance spectroscopy (MRS) usually shows a low $N$-acetylaspartate peak and a lack of elevated choline-containing component (Cho) or Cho- $\mathrm{Cr}$ ratio $(\mathrm{Cho} / \mathrm{Cr})[67]$. These features help to identify the DNT lesion and distinguish it from other low-grade gliomas.

\section{Histopathology}

Typically, DNT is characterized by intracortical nodules with columnar architecture of uniform oligodendrocyte-like cells within microcystic background (Fig. 2A and B). It exhibits a distinct morphology with a so-called specific glioneuronal element (Fig. 2C). This element consists predominantly of small oligodendrocyte-like cells arranged in a columnar orientation along parallel bundles of axons (Fig. 2D). They are usually oriented perpendicular to the cortical/pial surface [20]. Microcysts of various shape and size are lined by small, uniform cells of oligodendrocyte-like morphology (Fig. 2E and F). The large neurons are scattered within microcystic areas, sometimes making an impression that they "float" in mucin-filled background (Fig. 3A). The neurons usually exhibit morphology of normal pyramidal neurons (Fig. 3B) and may be considered as pre-existing cortical neuronal cells. Moreover, the various amount of astrocytes might be scattered in the DNT lesion. The above multinodular architecture of the lesion accompanied by the presence of "floating neurons" are the most distinctive morphological features of DNT.

Sometimes, the DNT may exhibit a growth pattern resembling diffuse gliomas. In some cases the DNT lesion consists of solid areas with oligodendrocyte-like cells and thin-walled microvessels (Fig. 3C). Delicate, so-called "chicken-wire" vasculature resembling oligodendroglioma can be visible (Fig. 3D). Microvascular proliferation with a telangiectatic pattern could be also seen. Some areas of DNT show hypercellularity with honeycomb appearance of monomorphic cells with round nuclei surrounded by clear haloes or ribbon-like palisades highly similar to oligodendroglioma (Fig. 3E and F). However, perinuclear satellitosis is not characteristic for DNTs lesions. Occasionally, the compact piloid tissue with pleomorphic neoplastic cells might resemble pilocytic astrocytoma.
Intriguingly, Komori et al. [33] claimed that DNT is rather a glial than glioneuronal tumour, similar to oligodendroglioma, thus it should be classified as a non-infiltrative oligodendroglioma. The research performed on DNT samples using morphometric evaluation and immunohistochemical studies documented staining for Neu-N, a neuronal nuclear antigen being a marker of neurons, and Olig-2, a transcription factor important for motoneuron [42,52] and oligodendrocyte differentiation [70]. They found that double immunohistochemical staining showed co-localization of Olig-2 and Neu-N. The distribution of Neu-N positive nuclei was similar in the tumour tissue and the adjacent cortex. Moreover, the density of Neu-N positive nuclei was lower in the tumours located in the white matter compared to those from grey matter. They suggest that probably Neu-N positive cells are entrapped in granular and pyramidal neuronal cells [33].

Three histopathological forms of DNT have been described, including: 1) simple, 2) complex and 3) nonspecific and diffuse. The last form was created based on the statement that the diffuse form of DNT corresponds to a non-specific variant $[8,19,29]$. However, the diagnosis and definition of the non-specific type of DNT is controversial.

The simple form of DNT is composed of the specific glioneuronal element with oligodendrocyte-like cells arranged in columns. The bundles of axons and floating neurons are dispersed in a mucin-like background.

The complex form of DNT exhibits heterogeneous morphology with multinodular architecture. Except a specific glioneuronal element mentioned above, it is characterized by presence of glial nodules resembling oligodendrocytic or astrocytic population [18].

Diagnosis of a non-specific and diffuse form of DNT is challenging because of lack of the specific glioneuronal element and no multinodular structure. This form of DNT exhibits glial components similar to glial nodules of the complex DNT type. It is difficult to distinguish this DNT variant from other glial tumours. The non-specific and diffuse form of DNT might be histologically similar to glioma, ganglioglioma, pilocytic astrocytoma or diffuse astrocytoma [61,65]. Nevertheless, the clinical presentation with chronic seizures, cortical localization on neuroimaging and a follow-up are similar to typical DNT. Thus, the clinical data are mandatory to consider the identification of the non-specific and diffuse form of DNT [19]. 

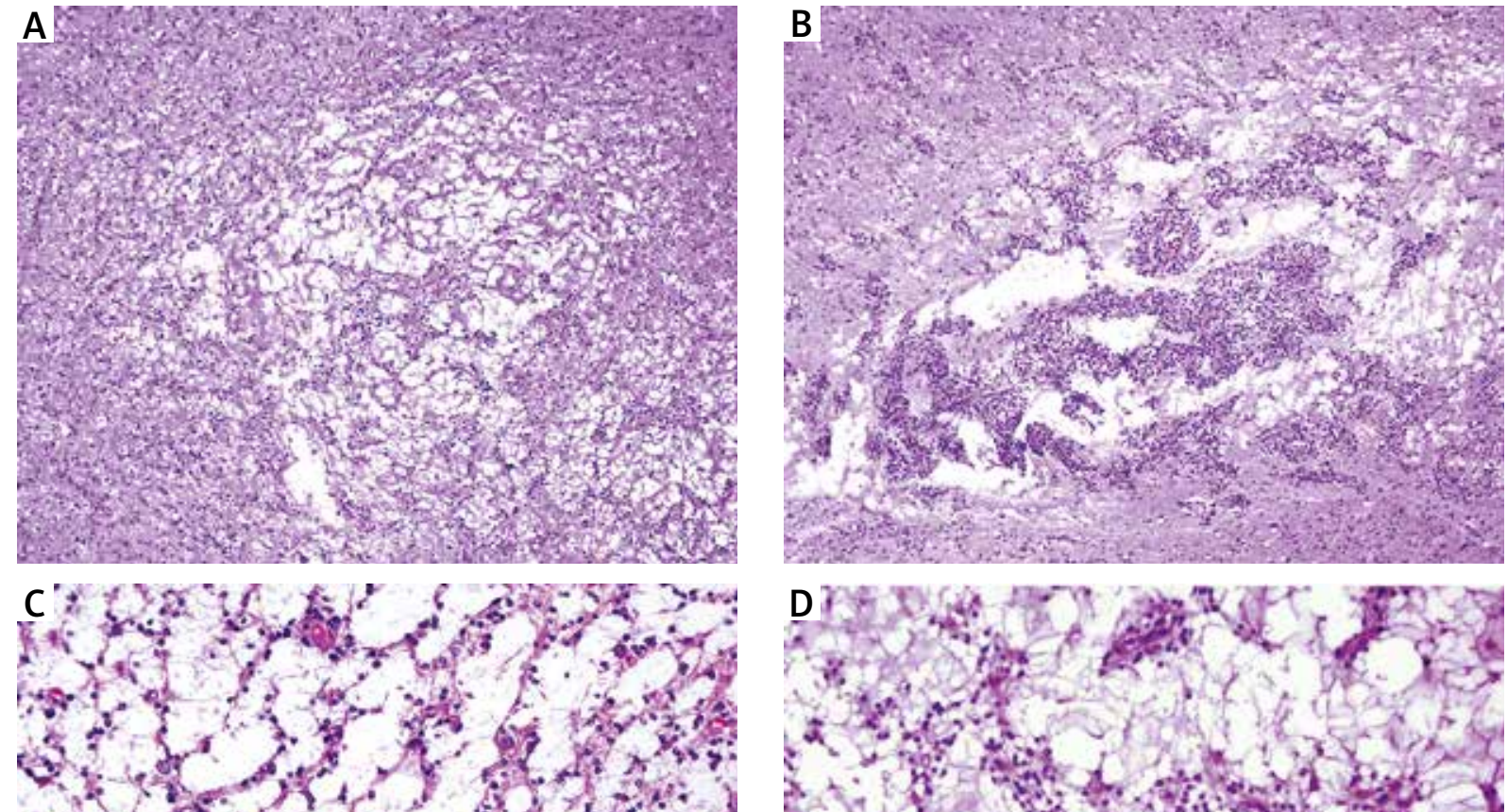

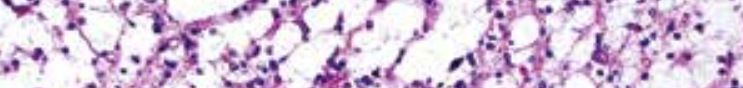
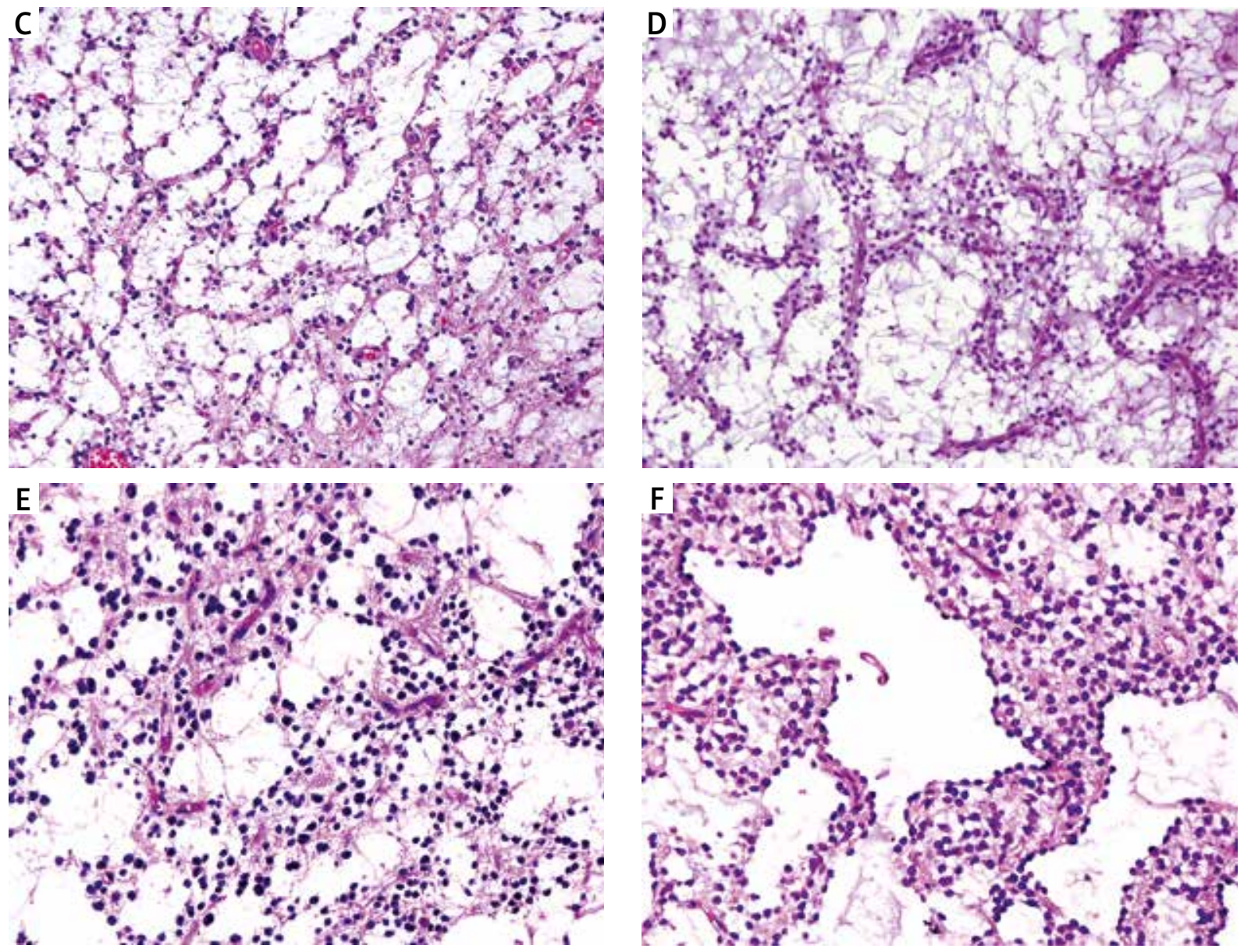

Fig. 2. Histopathology of dysembryoplastic neuroepithelial tumour (DNT), H\&E staining. A, B) Intracortical nodules with microcystic, vacuolated background. C) Specific glioneuronal component with typical columnar architecture. D) Microcystic region consisting of mucin-rich background and a small oligodendrocyte-like component arranged along parallel rows of axons. E) Microcystic architecture with uniform oligodendrocyte-like cells and tiny vessels. F) Large microcysts lined by small oligodendrocyte-like cells (from own archival surgical material). 

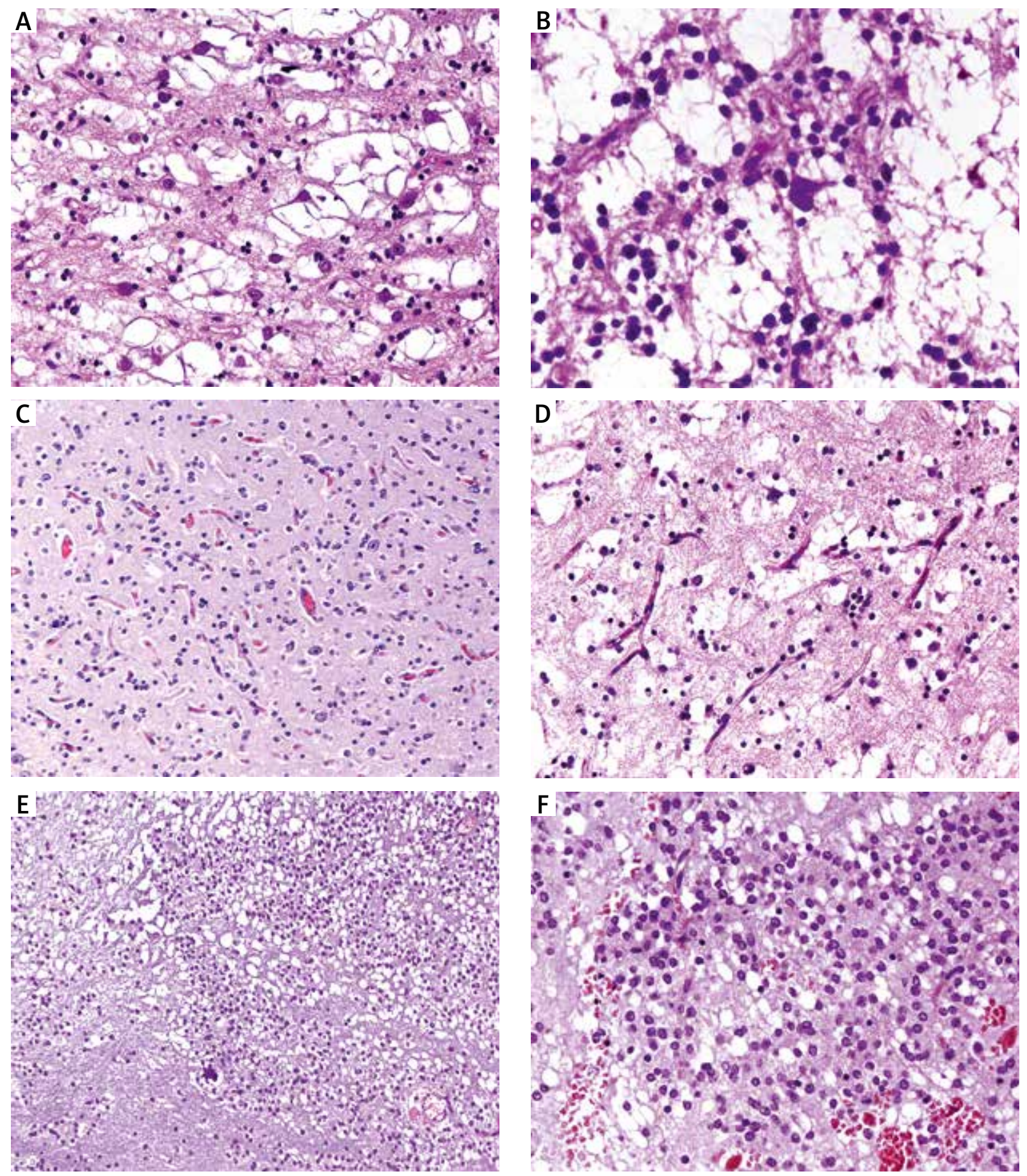

Fig. 3. Histopathology of dysembryoplastic neuroepithelial tumour (DNT), H\&E staining. A) Specific glioneuronal element with alveolar arrangement of oligodendrocyte-like cells and numerous interspersed floating neurons. B) Typical glioneuronal element with an easily visible floating neuron. C) Solid growth pattern with oligodendrocyte-like cells and small, thin-walled vessels. D) Delicate branching capillaries and small, uniform cells resembling oligodendroglioma. E) Diffuse growth pattern with honeycomb appearance mimicking oligodendroglioma. F) Small, monomorphic cells with round nuclei surrounded by clear haloes similar to oligodendroglioma (from own archival surgical material). 
In accordance with the benign nature of DNT, cytological atypia or mitotic activity are uncommon features and Ki-67 proliferative index is usually low, ranges from 0 to about $1.6 \%$ [22].

Moreover, DNT may be associated with focal cortical dysplasia (FCD), hippocampal sclerosis and ganglioglioma [50,51,63]. Cortical dysplasia accompanying DNT lesions is identified as FCD type IIIb, according to the criteria of the classification of the International League Against Epilepsy [6]. The foci of cortical dysplasia often coexist with the simple and non-specific type of DNT $[18,19]$.

Differences between various forms of DNT also manifest in epileptogenicity. Chassoux et al. [15], using stereo-electroencephalography, compared epileptogenicity in different histological variants of DNT. Interestingly, they have found that the epileptogenic zone is localized in the tumour in a simple and complex form and is more widespread in most non-specific DNTs. The difference is pronounced especially in non-specific, temporal DNTs with extensive focal cortical dysplasia (FCD). However, the relationship with FCD does not unambiguously explain this discrepancy.

In addition, rare mixed tumours composed of a DNT lesion with components of rosette forming glioneuronal tumour [38], pilocytic astrocytoma [44] or pleomorphic xanthoastrocytoma [30] have been described.

\section{Immunophenotypic profile}

Markers useful in characterization of immunophenotype of DNT include S-100 protein, transcriptional factor OLIG-2, glial fibrillary acid protein (GFAP), NeuN, microtubule-associated protein 2 (MAP-2), CD34, nestin, and calbindin.

The small oligodendrocyte cells express S-100 protein (Fig. 4A) and OLIG-2, whereas they are negative for GFAP. The neuronal component consisting of "floating neurons" shows neuronal markers such as NeuN, MAP-2 and synaptophysin. GFAP can be expressed in the astrocytes scattered in the background (Fig. 4B).

MAP2 protein was observed in different proportions among DNT variants. It is expressed during development of the central nervous system as well as in neurons and glial cells in the adult brain $[58,64]$. MAP2 expression in oligodendrocyte-like cells and glial elements was observed significantly more often in non-specific DNTs than in the simple or complex form. Co-expression of MAP2 and CD34 was significantly more frequent in the non-specific than in complex and simple form [62]. However, the difference in MAP2 expression among different types of DNT has not been confirmed [65].

A cell-surface transmembrane protein CD34 can be found in some cases of DNT. It is commonly used as a marker of hematopoietic stem, progenitor cells and vascular endothelial cells, which is associated with increased proliferation and abrogated cell differentiation [45]. CD34 staining was observed in the perikaryal membrane of neuronal cells, cytoplasm of oligodendrocyte-like cells, pericellular stroma and stellate cells with astroglial morphology. Irrespective of the classification to the non-specific or
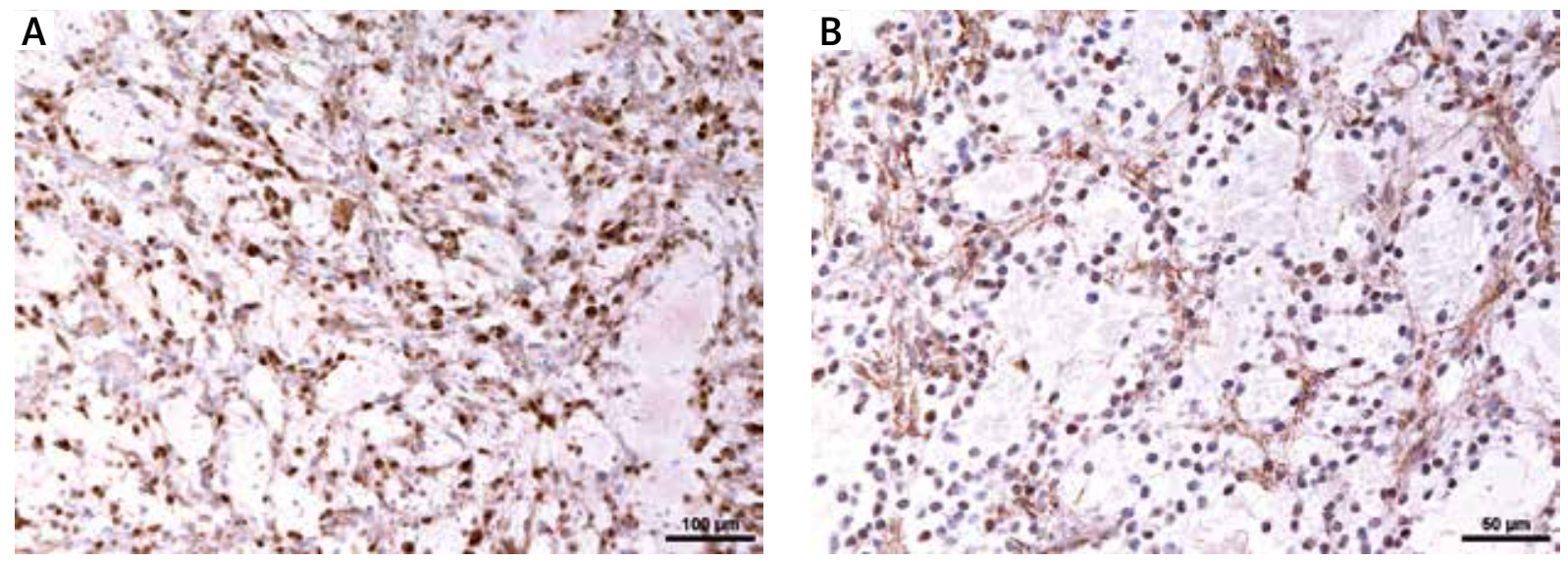

Fig. 4. Immunohistochemistry of dysembryoplastic neuroepithelial tumour (DNT). A) S-100 protein immunopositivity in oligodendrocyte-like elements. B) Glial fibrillary acid protein (GFAP) reactivity in the astrocytes scattered in the background (from own archival surgical material). 
diffuse form, CD34 expression in both types of DNT was found to be similar. Statistically significant differences of immunohistochemical staining for CD34 among three main histological types of DNT were observed in two studies. The highest expression of CD34 was noticed for the non-specific type compared with simple and complex types [62,65].

Expression of CD34 and nestin was found to be the highest in the non-specific and diffuse form, but there was a difference in expression of these markers in the simple type $[61,62]$. However, Thom et al. [65] observed a statistically significant correlation between CD34 and nestin staining in particular forms. Nestin is expressed during development of the central nervous system and in the majority of proliferating brain progenitor cells, thus it is considered as a neural stem cell marker [40]. Expression of nestin and CD34 was considerably higher in the non-specific and diffuse DNTs, which may suggest that it is a less differentiated form. Nevertheless, it is not related to higher malignancy [65].
Furthermore, the non-specific type and mixed DNT/GG tumours were characterized by a significantly higher expression of calbindin [65], a calcium binding protein expressed in neuronal cells [4].

\section{Molecular findings}

The main molecular findings are connected with $B R A F$ alterations and activation of RAS/ERK, PI3K/AKT and mTOR signalling pathways.

BRAF is a RAF family member displaying the highest basal activity and being considered to play an important role in tumorigenesis $[13,57]$ It is implicated in the so-called mitogen-activated protein kinase (MAPK) pathway [39].

Chappé et al. [13] found BRAFV600E mutation in ca. $30 \%$ of DNT. Analysis was performed by a combination of polymerase chain reaction-high resolution melting (PCR-HRM), direct sequencing and immunohistochemistry as a complementary method.

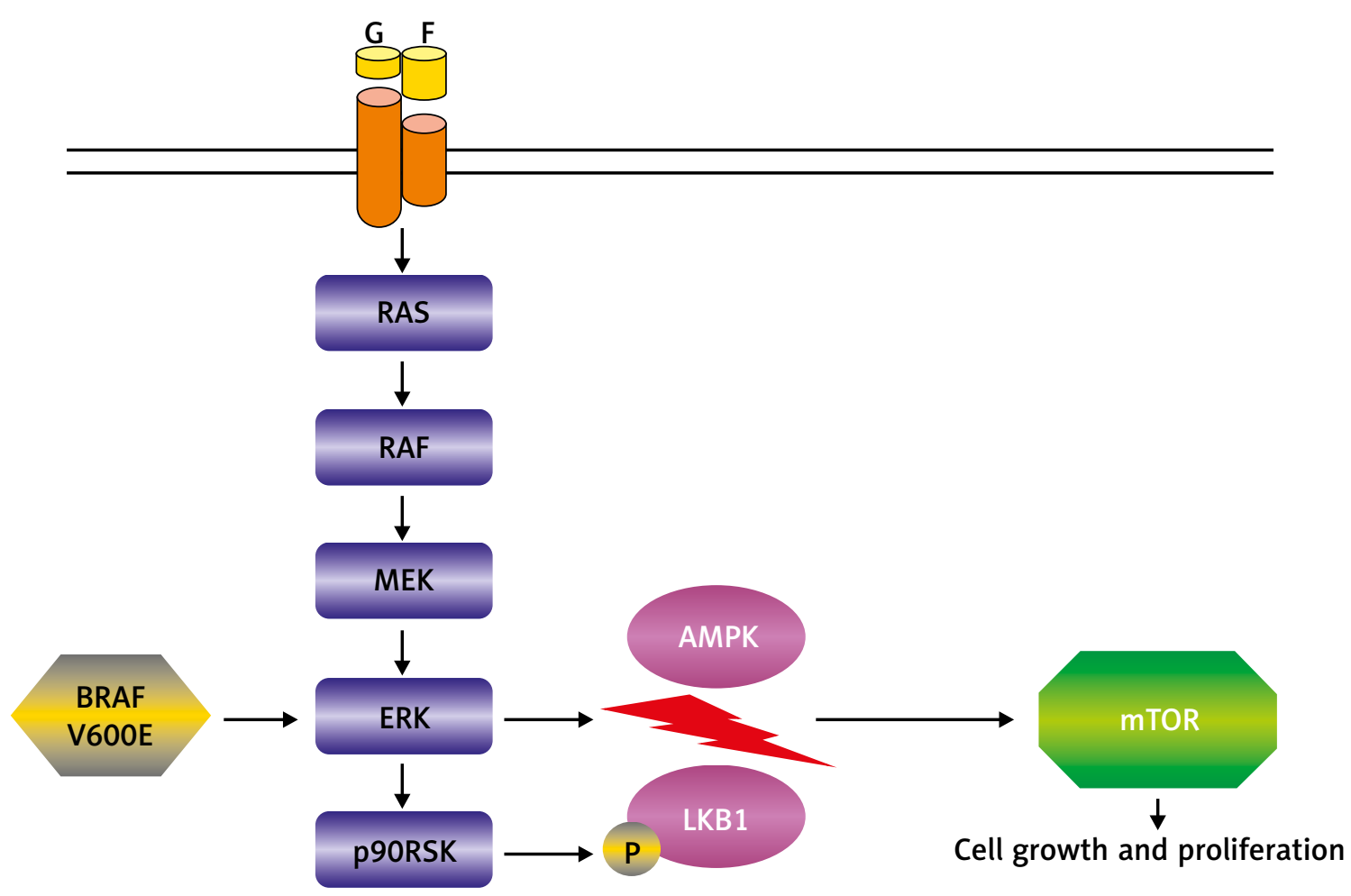

Fig. 5. Diagram illustrating probable mechanism leading to mammalian target of rapamycin (mTOR) activation. Activation of RAS/mitogen activated protein kinase (ERK) - p90 ribosomal six kinase (p90RSK) pathway as well as activating mutation of BRAFV600E may impact on separation of liver kinase B1 (LKB1) from AMP-activated protein kinase (AMPK), what leads to mTOR activation. However, the mechanism seems to be independent of phosphorylation of LKB1 by p90RSK. 
High occurrence of BRAFV600E mutations (51\%) was detected in a study performed on a group of 51 DNT cases [34]. Furthermore, the authors have found that mutations were significantly more frequent in tumours with extratemporal location.

In another direct sequencing study performed on 77 samples of DNT, frequent BRAFV600E mutation was shown in approximately $30 \%$ of cases [47]. Intriguingly, the authors did not find BRAFV60OE mutation in the simple form of DNT. They also reported immunohistochemical co-localization of BRAF V600E-mutated protein with phosphorylated ribosomal S6 protein (pS6) and phosphorylated liver kinase B1 (pLKB1), as well as they found a significant correlation between presence of BRAFV600E mutations and pS6 expression in dysplastic neurons in DNTs. The pS6 is a marker of mTOR activation. Thus, a mutation in BRAF might indirectly activate mTOR by the LKB1/AMP-activated protein kinase (AMPK) pathway (Fig. 5). LKB1 with its downstream effector AMPK may act as a tumour suppressor by downregulation of mTOR activity [26]. The crosstalk LKB1/AMPK with RAS/ERK/p90RSK pathway was previously described in melanoma cell cultures [25]. BRAF copy number gain was reported for the first time in DNT tumours by Kakkar et al. [32]. Alterations in the BRAF gene, and activation of mTOR and MAPK signalling pathways are suggested to play an important role in pathogenesis of DNT, and may be considered as a target for future treatment.

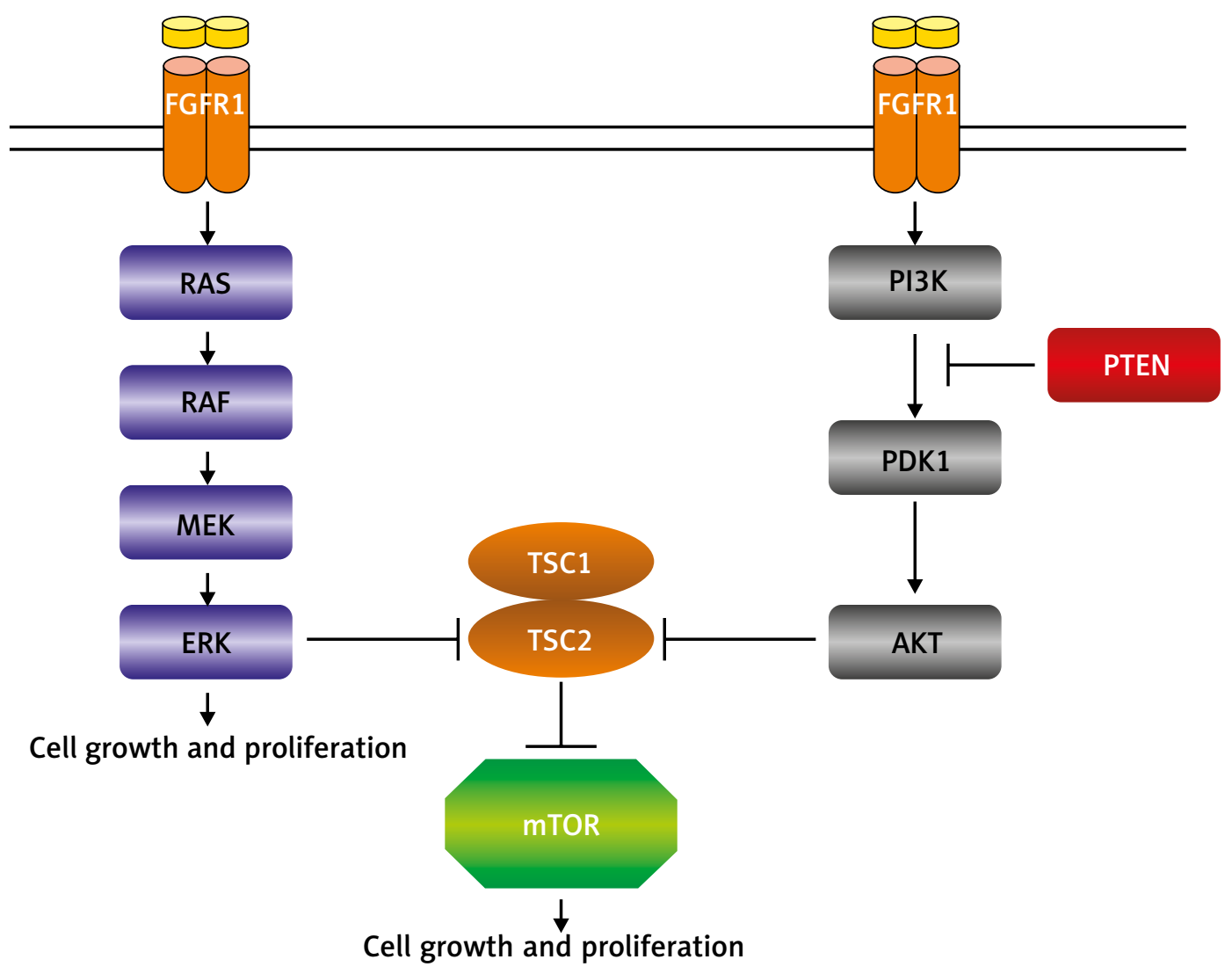

Fig. 6. Diagram illustrating activation of signalling pathways, which activation was examined in dysembryoplastic neuroepithelial tumour (DNT). Activation of the receptor, i.e. fibroblast growth factor receptor 1 (FGFR1) leads to RAS activation and consequently to phosphorylation of mitogen activated protein kinase (ERK) through cascade of protein kinases: RAF and mitogen activated protein kinase (MEK). Phosphorylated ERK may activate transcription factors as well as impact on tuberous sclerosis complex 2 (TSC2) - an inhibitor of mammalian target of rapamycin (mTOR). Lack of mTOR suppression implies cell growth and proliferation. Similarly to ERK, also phosphorylation of AKT by 3-phosphoinositide-dependent kinase 1 (PDK1) leads to mTOR activation. Phosphatase and tensin homolog (PTEN) might reverse phosphatidylinositol-3-kinase (PI3K) phosphorylation and inhibit activation of downstream proteins of the pathway. 
The targeted therapies might be especially useful in patients with incomplete surgical resection and persistent seizures.

On the contrary, the study of Boer et al. [9] showed that activation of the mTOR pathway is similar to the control human brain. However, it should be stressed that this study was performed on nine samples of the simple DNT type, which may explain lack of active mTOR. Immunocytochemical analysis of activation of the PI3K/AKT pathway also revealed no differences as compared to the control brain.

Pathogenesis of DNT may also include phosphatase and tensin homolog (PTEN), a tumour suppressor protein, which is involved in regulation of the PI3K/AKT pathway [28] (Fig. 6). However, mutations of the PTEN gene were not detected using single strand conformation polymorphism (SSCP) analysis and direct sequencing in a sample of DNT [21]. Furthermore, it must be stressed that this investigation was performed on one DNT sample only.

The possible way of RAS/ERK, as well as PI3K/AKT activation, is phosphorylation of fibroblast growth factor receptor 1 (FGFR1). Investigations by Zhang et al. [69] on paediatric low grade gliomas showed duplication of the tyrosine kinase domain of FGFR1. It leads to autophosphorylation of the receptor and consequently RAS/ERK and PI3K/AKT upregulation.

Recent studies have shown genetic alterations of FGFR 1 in $82 \%$ of examined DNTs, where dominant types of alterations were tyrosine kinase domain duplications and single nucleotide variations [53].

Furthermore, high frequency of FGFR 1 mutations was presented by Rivera et al. [56]. Interestingly, they distinguished two groups of tumours from collected samples, which were primarily diagnosed as DNTs. Histopathological revision using current WHO diagnostic criteria distinguished the group of typical DNTs with characteristic glioneuronal elements. The non-DNT group was composed of the other tumours whose histopathological view and clinical features might correspond to the non-specific type of DNT. Mutations of FGFR1 were more frequent in specific DNT (58\%) in comparison to the non-DNT group (19\%). The main type of alteration in the specific DNT group was tyrosine kinase domain duplication. Moreover, mutation of BRAFV600E was observed in $22.6 \%$ of non-DNTs, while it was not detected in specific DNT.

In addition, the authors described germline FGFR 1 mutation in the three familial cases with multino- dular DNTs. It was localized in the region coding tyrosine kinase domain. The tumours, which were resected from proband's children, shared somatic "hot spot" mutations [56].

Prabowo et al. [48] studied chromosomal copy number aberrations in DNTs and gangliogliomas. Using whole genome sequencing, they found a wide spectrum of copy number aberrations with chromosome 5 and 7 being the most often changed ones. Furthermore, FISH analysis performed on five samples of DNT showed that copy number gain on chromosome 7 is detected in cells with glial morphology, but not in cells with neuronal morphology.

\section{The involvement of the local microenvironment in tumour development}

It is plausible that the development of DNT may be also affected by brain parenchyma and elements, which constitute environment of the tumour.

Aronica et al. [3] have found that the amount of cells of the microglia/macrophage lineage in DNTs and gangliogliomas was much higher compared to the control brain. In the majority of samples there was a diffuse distribution of HLA-DR immunoreactivity. The positive cells revealed morphology of activated microglia.

Another study performed on samples of epilepsy-associated lesions DNTs, gangliogliomas and focal cortical dysplasias, has shown positive immunostaining for interleukin $1 \beta$ (IL-1 $\beta$ ) and IL-1 receptor type I (IL-1RI) in neurons as well as in astrocytes and microglial cells. Noteworthy, immunoreactivity of interleukin 1 receptor antagonist (IL-1Ra), which may act as an inhibitory control of IL-1 $\beta$, was lower than immunoreactivity of IL-1 $\beta$ and IL-1RI in examined samples and its extension was negatively related to the duration of seizures [55].

\section{Differential diagnosis}

The diagnosis of DNT requires consideration of clinical, neuroradiological and pathological data. In cases with incomplete resection and limited tissue samples the correct diagnosis might be doubtful. Moreover, the particular forms of DNT, especially the non-specific and diffuse form can be mistakenly identified as diffuse gliomas. However, in the differential diagnosis of DNT, first of all, the oligodendroglioma and diffuse astrocytoma should be considered. 
Immunohistochemical staining with specific marker as S-100, synaptophysin, CD34 or BRAF protein and analysis of genetic aberrations might be helpful to differentiate DNT from other brain tumours.

Evaluation of $1 p / 19 q$ status as well as mutation of the IDH1 gene in codon $132(\mathrm{R} 132 \mathrm{H})$ may be useful to distinguish DNT from oligodendroglioma. Both, loss of heterozygosity for $1 p, 17 p$ and $19 q$ [31, 49] and IDH1 gene mutation [10] are not identified in DNTs and their presence excludes the diagnosis of DNT lesion. Also, the IDH1 and TP53 mutation is helpful in identification of diffuse astrocytomas and distinguish them from DNT. Moreover, strong GFAP immunopositivity of neoplastic cells is related with astrocytic differentiation in pure astroglial tumours. The low proliferative index Ki67 might indicate the benign DNT tumour rather than diffuse gliomas.

\section{Treatment and outcome}

The predominant and the most effective treatment in DNT symptomatic cases is a total tumour resection. It leads to a seizure-free outcome even in more than $80 \%$ of patients during at least a one-year observation [12]. Even better results may be obtained by the complete resection of the tumour together with the epileptogenic zone [15]. Thus, it is believed that the majority of DNT lesions are surgically curable.

However, the cases of DNT with recurrences and malignant transformations of initially recognized benign tumours have been sporadically reported $[1,27,68]$. The malignant transformation of DNT seems to be unique, however it argues the possibility of more aggressive behaviour of this originally described benign lesion [6]. Time of recurrence after the initial resection may ranges between several months to several years. Occasionally, another brain tumour with higher malignancy has been detected after DNT resection, including atypical teratoid rhabdoid tumour (AT/RT), a highly aggressive embryonal brain tumour [43]. This emphasizes the importance of the prolonged period of clinical and neuroimaging follow-up of DNT resected lesions.

\section{Prognosis}

Most commonly, the DNT resection results in stabilization of the clinical course, even after subtotal resection. The meta-analysis conducted on 910 patients with DNT or ganglioglioma showed that the seizure outcome depends on the duration and type of epilepsy, and extensiveness of resection [24]. Secondarily generalized seizures, longer than one-year epilepsy and subtotal lesionectomy were connected with a worse seizure outcome. It was documented that there were no significant differences in the seizure outcome between DNT and ganglioglioma.

Another analysis conducted on data of 78 patients operated on for DNT confirmed a statistically significant correlation between a shorter duration of epilepsy before the surgery and a more favourable outcome [14].

Furthermore, a study on paediatric patients with glioneuronal tumours (ganglioglioma and DNT) showed that a shorter duration of seizures was connected with a better cognitive functioning [54]. It might indicate a negative effect of epilepsy as well as antiepileptic drugs on cognitive development.

Another study revealed the presence of cells of the microglial/macrophage cell system and indicated a significant functional correlation between HLA-DR positive cells and the duration of epilepsy and also a preoperative seizure frequency in glioneuronal tumours (gangliogliomas and DNTs) [3]. Moreover, the connection between the presence of microglial cells and the seizure outcome after surgery was found. The presence of microglial cells was connected with an inflammatory process that might have a negative effect on the disease process. The authors pointed out that the duration of epilepsy had an impact on the occurrence of microglial cells and probably also on the inflammation, which developed during the neoplasm growth.

\section{Final considerations}

The theory that DNTs are only glial tumours, whereas the neuronal component consists of entrapped normal neurons, demands further investigations on a larger group, which will contain also the non-specific and diffuse type. On the one hand, the occurrence of copy number aberrations only in the cells with glial morphology is in accordance with the mentioned theory. But, on the other hand, the mutations in BRAF were found in neuronal cells. Moreover, the FISH analysis of copy number aberrations should be performed on a higher number of cases to ensure it.

Differences in immunophenotype of distinct types of DNT may suggest a distinct origin of the non-specific and diffuse type or might indicate that it is an earlier form of DNT, which might progress 
into the simple or complex form. The diagnosis of non-specific and diffuse variant of DNT is still not obvious. Moreover, the changes in classification of tumours associated with long-term epilepsy are postulated. The idea is to categorize all three types of DNT into different groups of tumours [7]. The proposed classification is based on histopathological features as well as immunohistochemical labelling (CD34, MAP2) and testing for IDH1 mutations.

Histological categorization might be supported by differences in molecular mechanisms involved in pathogenesis. BRAFV600E mutations seem to be implicated mainly in non-specific and diffuse types of DNT, while FGFR1 mutations were observed mostly in specific DNTs.

Moreover, the microglia cells and released cytokines seem to be implicated in the DNT pathological process and they are related to the clinical presentation. Probably, the role of microglia is associated with IL-1 $\beta$ release and induction of the inflammatory process, which causes seizures.

Summarizing, DNT is a benign tumour lesion of a distinct clinical and neuroimaging picture but heterogonous, often confusing morphology, uncertain histogenesis and not fully defined molecular background.

\section{Disclosure}

Authors report no conflict of interest.

\section{References}

1. Aggarwal A, Salunke P, Sodhi HB, Vasishta RK, Gowda KK. Dysembryoplastic neuroepithelial tumor transforming into malignancy: a case report. Neurol India 2014; 62: 323-325.

2. Altinors N, Calisaneller T, Gulsen S, Ozen O, Onguru O. Intraventricular dysembryoplastic neuroepithelial tumor: case report. Neurosurgery 2007; 61: E1332-1333; discussion E1333.

3. Aronica E, Gorter JA, Redeker S, Ramkema M, Spliet WG, van Rijen PC, Leenstra S, Troost D. Distribution, characterization and clinical significance of microglia in glioneuronal tumours from patients with chronic intractable epilepsy. Neuropathol Appl Neurobiol 2005; 31: 280-291.

4. Baimbridge KG, Celio MR, Rogers JH. Calcium-binding proteins in the nervous system. Trends Neurosci 1992; 15: 303-308.

5. Bilginer B, Yalnizoglu D, Soylemezoglu F, Turanli G, Cila A, Topcu M, Akalan N. Surgery for epilepsy in children with dysembryoplastic neuroepithelial tumor: clinical spectrum, seizure outcome, neuroradiology, and pathology. Childs Nerv Syst 2009; 25: 485 491.

6. Blümcke I, Thom M, Aronica E, Armstrong DD, Vinters HV, Palmini A, Jacques TS, Avanzini G, Barkovich AJ, Battaglia G, Becker A Cepeda C, Cendes F, Colombo N, Crino P, Cross JH, Delalande O,
Dubeau F, Duncan J, Guerrini R, Kahane P, Mathern G, Najm I, Ozkara C, Raybaud C, Represa A, Roper SN, Salamon N, SchulzeBonhage A, Tassi L, Vezzani A, Spreafico R. The clinicopathologic spectrum of focal cortical dysplasias: a consensus classification proposed by an ad hoc Task Force of the ILAE Diagnostic Methods Commission. Epilepsia 2011; 52: 158-174.

7. Blumcke I, Aronica E, Urbach H, Alexopoulos A, Gonzalez-Martinez JA. A neuropathology-based approach to epilepsy surgery in brain tumors and proposal for a new terminology use for longterm epilepsy-associated brain tumors. Acta Neuropathol 2014; 128: 39-54.

8. Bodi I, Selway R, Bannister P, Doey L, Mullatti N, Elwes R, Hona$\operatorname{var}$ M. Diffuse form of dysembryoplastic neuroepithelial tumour: the histological and immunohistochemical features of a distinct entity showing transition to dysembryoplastic neuroepithelial tumour and ganglioglioma. Neuropathol Appl Neurobiol 2012; 38: 411-425.

9. Boer K, Troost D, Timmermans W, van Rijen PC, Spliet WG, Aronica E. Pi3K-mTOR signaling and AMOG expression in epilepsy-associated glioneuronal tumors. Brain Pathol 2010; 20: 234244.

10. Capper D, Reuss D, Schittenhelm J, Hartmann C, Bremer J, Sahm F, Harter PN, Jeibmann A, von Deimling A. Mutation-specific IDH1 antibody differentiates oligodendrogliomas and oligoastrocytomas from other brain tumors with oligodendroglioma-like morphology. Acta Neuropathol 2011; 121: 241-252.

11. Cataltepe O, Marshall P, Smith TW. Dysembryoplastic neuroepithelial tumor located in pericallosal and intraventricular area in a child. Case report. J Neurosurg Pediatr 2009; 3: 456-460.

12. Chang EF, Christie C, Sullivan JE, Garcia PA, Tihan T, Gupta N, Berger MS, Barbaro NM. Seizure control outcomes after resection of dysembryoplastic neuroepithelial tumor in 50 patients. J Neurosurg Pediatr 2010; 5: 123-130.

13. Chappe C, Padovani L, Scavarda D, Forest F, Nanni-Metellus I, Loundou A, Mercurio S, Fina F, Lena G, Colin C, Figarella-Branger D. Dysembryoplastic neuroepithelial tumors share with pleomorphic xanthoastrocytomas and gangliogliomas BRAF(V600E) mutation and expression. Brain Pathol 2013; 23: 574-583.

14. Chassoux F, Rodrigo S, Mellerio C, Landre E, Miquel C, Turak B, Laschet J, Meder JF, Roux FX, Daumas-Duport C, Devaux B. Dysembryoplastic neuroepithelial tumors: an MRI-based scheme for epilepsy surgery. Neurology 2012; 79: 1699-1707.

15. Chassoux F, Landre E, Mellerio C, Laschet J, Devaux B, Daumas-Duport C. Dysembryoplastic neuroepithelial tumors: epileptogenicity related to histologic subtypes. Clin Neurophysiol 2013; 124: 1068-1078.

16. Daghistani R, Miller E, Kulkarni AV, Widjaja E. Atypical characteristics and behavior of dysembryoplastic neuroepithelial tumors. Neuroradiology 2013; 55: 217-224.

17. Daumas-Duport C, Scheithauer BW, Chodkiewicz JP, Laws ER, Jr, Vedrenne C. Dysembryoplastic neuroepithelial tumor: a surgically curable tumor of young patients with intractable partial seizures. Report of thirty-nine cases. Neurosurgery 1988; 23: 545-556.

18. Daumas-Duport C. Dysembryoplastic neuroepithelial tumours. Brain Pathol 1993; 3: 283-295. 
19. Daumas-Duport C, Varlet P, Bacha S, Beuvon F, Cervera-Pierot P, Chodkiewicz JP. Dysembryoplastic neuroepithelial tumors: nonspecific histological forms - a study of 40 cases. J Neurooncol 1999; 41: 267-280.

20. Daumas-Duport C PT, Lantos PL. Dysembryoplastic neuroepithelial tumor. In: Pathology and genetics of tumors of the central nervous system. Kleihus P, Cavenee WK (eds.). IARC Press, Lyon 2000; pp. 103-104.

21. Duerr EM, Rollbrocker B, Hayashi Y, Peters N, Meyer-Puttlitz B, Louis DN, Schramm J, Wiestler OD, Parsons R, Eng C, von Deimling A. PTEN mutations in gliomas and glioneuronal tumors. Oncogene 1998; 16: 2259-2264.

22. Duggal N, Taylor R, Zou GY, Hammond RR. Dysembryoplastic neuroepithelial tumours: clinical, proliferative and apoptotic features. J Clin Pathol 2008; 61: 127-131.

23. Emmez H, Kale A, Egemen E, Eser P, Kaymaz M, Pasaoglu A Intraventricular dysembryoplastic neuroepithelial tumour: case report. Neurol Neurochir Pol 2012; 46: 192-195.

24. Englot DJ, Berger MS, Barbaro NM, Chang EF. Factors associated with seizure freedom in the surgical resection of glioneuronal tumors. Epilepsia 2012; 53: 51-57.

25. Esteve-Puig R, Canals F, Colome N, Merlino G, Recio JA. Uncoupling of the LKB1-AMPKalpha energy sensor pathway by growth factors and oncogenic BRAF. PLoS One 2009; 4: e4771.

26. Faubert B, Vincent EE, Poffenberger MC, Jones RG. The AMP activated protein kinase (AMPK) and cancer: many faces of a metabolic regulator. Cancer Lett 2015; 356: 165-170.

27. Hammond RR, Duggal N, Woulfe JM, Girvin JP. Malignant transformation of a dysembryoplastic neuroepithelial tumor. Case report. J Neurosurg 2000; 92: 722-725.

28. Hers I, Vincent EE, Tavare JM. Akt signalling in health and dis ease. Cell Signal 2011; 23: 1515-1527.

29. Honavar M, Janota I, Polkey CE. Histological heterogeneity of dysembryoplastic neuroepithelial tumour: identification and differential diagnosis in a series of 74 cases. Histopathology 1999; 34: 342-356.

30. Ishizawa K, Terao S, Kobayashi K, Yoshida K, Hirose T. A neuroepithelial tumor showing combined histological features of dysembryoplastic neuroepithelial tumor and pleomorphic xanthoastrocytoma - a case report and review of the literature. Clin Neuropathol 2007; 26: 169-175.

31. Johnson MD, Vnencak-Jones CL, Toms SA, Moots PM, Weil R. Allelic losses in oligodendroglial and oligodendroglioma-like neoplasms: analysis using microsatellite repeats and poly merase chain reaction. Arch Pathol Lab Med 2003; 127: $1573-$ 1579.

32. Kakkar A, Majumdar A, Kumar A, Tripathi M, Pathak P, Sharma MC, Suri V, Tandon V, Chandra SP, Sarkar C. Alterations in BRAF gene, and enhanced mTOR and MAPK signaling in dysembryoplastic neuroepithelial tumors (DNTs). Epilepsy Res 2016; 127: 141-151.

33. Komori T, Arai N. Dysembryoplastic neuroepithelial tumor, a pure glial tumor? Immunohistochemical and morphometric studies. Neuropathology 2013; 33: 459-468.

34. Lee D, Cho YH, Kang SY, Yoon N, Sung CO, Suh YL. BRAF V600E mutations are frequent in dysembryoplastic neuroepithelial tumors and subependymal giant cell astrocytomas. J Surg Oncol 2015; 111: 359-364.
35. Lee DY, Chung CK, Hwang YS, Choe G, Chi JG, Kim HJ, Cho BK. Dysembryoplastic neuroepithelial tumor: radiological findings (including PET, SPECT, and MRS) and surgical strategy. J Neurooncol 2000; 47: 167-174.

36. Lee J, Lee BL, Joo EY, Seo DW, Hong SB, Hong SC, Suh YL, Lee M. Dysembryoplastic neuroepithelial tumors in pediatric patients. Brain Dev 2009; 31: 671-681.

37. Louis DN, Ohgaki H, Wiestler OD, Cavenee WK, Burger PC, Jouvet A, Scheithauer BW, Kleihues P. The 2007 WHO classification of tumours of the central nervous system. Acta Neuropathol 2007; 114: 97-109.

38. Matyja E, Grajkowska W, Kunert P, Marchel A. A peculiar histopathological form of dysembryoplastic neuroepithelial tumor with separated pilocytic astrocytoma and rosette-forming glioneuronal tumor components. Neuropathology 2014; 34: 491-498.

39. Mendoza MC, Er EE, Blenis J. The Ras-ERK and PI3K-mTOR pathways: cross-talk and compensation. Trends Biochem Sci 2011; 36: $320-328$

40. Michalczyk K, Ziman M. Nestin structure and predicted function in cellular cytoskeletal organisation. Histol Histopathol 2005; 20: 665-671.

41. Minkin K, Klein O, Mancini J, Lena G. Surgical strategies and seizure control in pediatric patients with dysembryoplastic neuroepithelial tumors: a single-institution experience. J Neurosurg Pediatr 2008; 1: 206-210.

42. Mizuguchi R, Sugimori M, Takebayashi $H$, Kosako $H$, Nagao M, Yoshida S, Nabeshima Y, Shimamura K, Nakafuku M. Combinatorial roles of olig2 and neurogenin2 in the coordinated induction of pan-neuronal and subtype-specific properties of motoneurons. Neuron 2001; 31: 757-771.

43. Nadi M, Ahmad T, Huang A, Hawkins C, Bouffet E, Kulkarni AV. Atypical Teratoid Rhabdoid Tumor Diagnosis after Partial Resection of Dysembryoplastic Neuroepithelial Tumor: Case Report and Review of the Literature. Pediatr Neurosurg 2016; 51: 191-198.

44. Nasit JG, Shah P, Zalawadia H. Coexistent dysembryoplastic neuroepithelial tumour and pilocytic astrocytoma. Asian J Neurosurg 2016; 11: 451.

45. Nielsen JS, McNagny KM. Novel functions of the CD34 family. J Cell Sci 2008; 121: 3683-3692.

46. Pietsch T HC, Varlet P, Blumcke I, Hirose T. Dysembryoplastic neuroepithelial tumour. In: WHO Classification of Tumors of the Central Nervous System. Louis DN, Oghaki H, Wiesttler OD, Cavenee WK, Elison DW (eds.). Revised $4^{\text {th }}$ Edition. IARC Press, Lyon 2016; pp. 132-135.

47. Prabowo AS, Iyer AM, Veersema TJ, Anink JJ, Schouten-van Meeteren AY, Spliet WG, van Rijen PC, Ferrier CH, Capper D, Thom M, Aronica E. BRAF V600E mutation is associated with mTOR signaling activation in glioneuronal tumors. Brain Pathol 2014; 24: 52-66.

48. Prabowo AS, van Thuijl HF, Scheinin I, Sie D, van Essen HF, lyer AM, Spliet WG, Ferrier CH, van Rijen PC, Veersema TJ, Thom M, Schouten-van Meeteren AY, Reijneveld JC, Ylstra B, Wesseling P, Aronica E. Landscape of chromosomal copy number aberrations in gangliogliomas and dysembryoplastic neuroepithelial tumours. Neuropathol Appl Neurobiol 2015; 41: 743-755. 
49. Prayson RA, Castilla EA, Hartke M, Pettay J, Tubbs RR, Barnett GH. Chromosome 1p allelic loss by fluorescence in situ hybridization is not observed in dysembryoplastic neuroepithelial tumors. Am J Clin Pathol 2002; 118: 512-517.

50. Prayson RA, Fong J, Najm I. Coexistent pathology in chronic epilepsy patients with neoplasms. Mod Pathol 2010; 23: 1097-1103.

51. Prayson RA, Napekoski KM. Composite ganglioglioma/dysembryoplastic neuroepithelial tumor: a clinicopathologic study of 8 cases. Hum Pathol 2012; 43: 1113-1118.

52. Preusser M, Budka H, Rossler K, Hainfellner JA. OLIG2 is a useful immunohistochemical marker in differential diagnosis of clear cell primary CNS neoplasms. Histopathology 2007; 50: 365-370.

53. Qaddoumi I, Orisme W, Wen J, Santiago T, Gupta K, Dalton JD, Tang B, Haupfear K, Punchihewa C, Easton J, Mulder H, Boggs K, Shao Y, Rusch M, Becksfort J, Gupta P, Wang S, Lee RP, Brat D, Peter Collins V, Dahiya S, George D, Konomos W, Kurian KM, McFadden K, Serafini LN, Nickols H, Perry A, Shurtleff S, Gajjar A, Boop FA, Klimo PD Jr, Mardis ER, Wilson RK, Baker SJ, Zhang J, Wu G, Downing JR, Tatevossian RG, Ellison DW. Genetic alterations in uncommon low-grade neuroepithelial tumors: BRAF, FGFR1, and MYB mutations occur at high frequency and align with morphology. Acta Neuropathol 2016; 131: 833-845.

54. Ramantani G, Kadish NE, Anastasopoulos C, Brandt A, Wagner K, Strobl K, Mayer H, Schubert-Bast S, Stathi A, Korinthenberg R, Feuerstein TJ, Mader I, van Velthoven V, Zentner J, Schulze-Bonhage A, Bast T. Epilepsy surgery for glioneuronal tumors in childhood: avoid loss of time. Neurosurgery 2014; 74: 648-657; discussion 657.

55. Ravizza T, Boer K, Redeker S, Spliet WG, van Rijen PC, Troost D, Vezzani A, Aronica E. The IL-1beta system in epilepsy-associated malformations of cortical development. Neurobiol Dis 2006; 24: 128-143.

56. Rivera B, Gayden T, Carrot-Zhang J, Nadaf J, Boshari T, Faury D, Zeinieh M, Blanc R, Burk DL, Fahiminiya S, Bareke E, Schüller U, Monoranu CM, Sträter R, Kerl K, Niederstadt T, Kurlemann G, Ellezam B, Michalak Z, Thom M, Lockhart PJ, Leventer RJ, Ohm M, MacGregor D, Jones D, Karamchandani J, Greenwood CM, Berghuis AM, Bens S, Siebert R, Zakrzewska M, Liberski PP, Zakrzewski K, Sisodiya SM, Paulus W, Albrecht S, Hasselblatt M, Jabado N, Foulkes WD, Majewski J. Germline and somatic FGFR1 abnormalities in dysembryoplastic neuroepithelial tumors. Acta Neuropathol 2016; 131: 847-863.

57. Roskoski R Jr. RAF protein-serine/threonine kinases: structure and regulation. Biochem Biophys Res Commun 2010; 399: 313-317.

58. Sanchez C, Diaz-Nido J, Avila J. Phosphorylation of microtubule-associated protein 2 (MAP2) and its relevance for the regulation of the neuronal cytoskeleton function. Prog Neurobiol 2000; 61 133-168.

59. Sharma MC, Jain D, Gupta A, Sarkar C, Suri V, Garg A, Gaikwad SB, Chandra PS. Dysembryoplastic neuroepithelial tumor: a clinicopathological study of 32 cases. Neurosurg Rev 2009; 32: 161169; discussion 169-170.

60. Spalice A, Ruggieri M, Grosso S, Verrotti A, Polizzi A, Magro G, Caltabiano R, Pavone P, Del Balzo F, Platania N, lannetti P. Dysembryoplastic neuroepithelial tumors: a prospective clinicopathologic and outcome study of 13 children. Pediatr Neurol 2010; 43: 395-402.
61. Sung CO, Suh YL. Different pattern of expression of nestin in the non-specific form of dysembryoplastic neuroepithelial tumors compared to the simple and complex forms. J Neurooncol 2009; 92: 7-13.

62. Sung CO, Suh YL, Hong SC. CD34 and microtubule-associated protein 2 expression in dysembryoplastic neuroepithelial tumours with an emphasis on dual expression in non-specific types. Histopathology 2011; 59: 308-317.

63. Takahashi A, Hong SC, Seo DW, Hong SB, Lee M, Suh YL. Frequent association of cortical dysplasia in dysembryoplastic neuroepithelial tumor treated by epilepsy surgery. Surg Neurol 2005; 64: 419-427.

64. Teng J, Takei Y, Harada A, Nakata T, Chen J, Hirokawa N. Synergistic effects of MAP2 and MAP1B knockout in neuronal migration, dendritic outgrowth, and microtubule organization. J Cell Biol 2001; 155: 65-76.

65. Thom M, Toma A, An S, Martinian L, Hadjivassiliou G, Ratilal B, Dean A, McEvoy A, Sisodiya SM, Brandner S. One hundred and one dysembryoplastic neuroepithelial tumors: an adult epilepsy series with immunohistochemical, molecular genetic, and clinical correlations and a review of the literature. J Neuropathol Exp Neurol 2011; 70: 859-878.

66. Wang F, Qiao G, Li X, Gui Q. A dysembryoplastic neuroepithelial tumor in the area of the caudate nucleus in a 57 -year-old woman: case report. Neurosurgery 2007; 61: E420; discussion E420.

67. Yu AH, Chen L, Li YJ, Zhang GJ, Li KC, Wang YP. Dysembryoplastic neuroepithelial tumors: magnetic resonance imaging and magnetic resonance spectroscopy evaluation. Chin Med J (Engl) 2009; 122: 2433-2437.

68. Zakrzewski K, Biernat W, Liberski PP, Polis L, Nowoslawska E. Pilocytic astrocytoma as a predominant component of a recurrent complex type DNT. Folia Neuropathol 2009; 47: 284-288.

69. Zhang J, Wu G, Miller CP, Tatevossian RG, Dalton JD, Tang B, Orisme W, Punchihewa C, Parker M, Qaddoumi I, Boop FA, Lu C, Kandoth C, Ding L, Lee R, Huether R, Chen X, Hedlund E, Nagahawatte P, Rusch M, Boggs K, Cheng J, Becksfort J, Ma J, Song G, Li Y, Wei L, Wang J, Shurtleff S, Easton J, Zhao D, Fulton RS, Fulton LL, Dooling DJ, Vadodaria B, Mulder HL, Tang C, Ochoa K, Mullighan CG, Gajjar A, Kriwacki R, Sheer D, Gilbertson RJ, Mardis ER, Wilson RK, Downing JR, Baker SJ, Ellison DW; St. Jude Children's Research Hospital-Washington University Pediatric Cancer Genome Project. Whole-genome sequencing identifies genetic alterations in pediatric low-grade gliomas. Nat Genet 2013; 45: 602-612.

70. Zhou Q, Wang S, Anderson DJ. Identification of a novel family of oligodendrocyte lineage-specific basic helix-loop-helix transcription factors. Neuron 2000; 25: 331-343. 